\title{
Capital humano, redes externas e innovación en la industria colombiana
}

\author{
ILIANA PÁEZ GABRIUNAS, Ph.D. ${ }^{1,2,3}$ \\ Directora, Centro de Liderazgo de la Facultad de Administración de Empresas, \\ Universidad Externado de Colombia, Colombia. \\ Estudiante Doctoral, Universidad de los Andes, Colombia. \\ Profesor afiliado, Universidad Externado de Colombia, Colombia. \\ iliana.paez@uexternado.edu.co; il.paez105@uniandes.edu.co
}

\begin{abstract}
RESUMEN
A partir de una muestra de industrias manufactureras en Colombia, se analiza la relación entre el capital humano, medido a través del nivel educativo, y los resultados de innovación, capacitación, redes e inversión de capital extranjero. Se identifican tres grupos de empresas -bajo nivel educativo, técnicas y profesionales- y se encontraron diferencias significativas entre estos grupos frente a los indicadores analizados. En general, existe una baja proporción de profesionales y técnicos en las industrias manufactureras colombianas estudiadas, aunque hay más profesionales que técnicos. El resultado principal es que los resultados de innovación, conectividad con redes externas, los esfuerzos de capacitación y las inversiones en actividades de innovación y de capital extranjero, son mayores en el conglomerado de profesionales.
\end{abstract}

Palabras clave. Innovación; capital humano; capacitación; redes; inversión extranjera.

Recibido: 29-jun-11, corregido: 26-abr-12 y aceptado: 26-jun-12

Clasificación JEL: M19; L60; L69

@

1 Este documento fue seleccionado en la convocatoria para enviar artículos, Call for Papers, realizada en el marco del “II Simposio Iberoamericano de Estudios Gerenciales: Una mirada interdisciplinar a la innovación”, organizado por la revista académica Estudios Gerenciales bajo la dirección de la Facultad de Ciencias Administrativas y Económicas de la Universidad Icesi; el evento tuvo lugar los días 12, 13 y 14 de octubre de 2011, en la ciudad de Cali (Colombia). Este documento fue presentado en las sesiones simultáneas del área de "Innovación en gestión del conocimiento".

2 Este artículo fue desarrollado en el seminario de investigación "Innovación en Países en Desarrollo" del programa de doctorado en Administración de la Universidad de los Andes, bajo la orientación del profesor Clemente Forero Pineda, Ph.D.

3 Dirigir correspondencia a: Universidad Externado de Colombia, Edificio Facultad de Administración de Empresas, Calle 12 \# 1-17 Este, Bogotá, Colombia. 


\section{Human capital, external networks, and innovation in the Colombian manufacturing industry}

This article uses a sample of manufacturing companies in Colombia for analyzing the relationship between human capital (measured based on educational level) and the results of innovation, training, networks, and foreign capital investment initiatives. Three different groups of companies were identified (namely, low educational level, technical, and professional companies), and significant differences were found between the three groups with regards to the indicators being reviewed. There are, in general, a low number of professionals and technicians in the Colombian manufacturing companies in the study, but there are a larger number of professionals than technicians. The main finding is that the results of innovation, connectivity with external networks, training efforts, investment in innovation activities, and foreign capital investment are greater in the professional cluster.

Keywords. Innovation; human capital; training; networks; foreign investment.

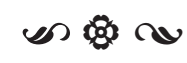

\section{Capital humano, redes externas e inovação na indústria colombiana}

A partir de uma amostra de indústrias de manufatura na Colômbia, se analisa a relação entre o capital humano, medido pelo nível educacional, e os resultados de inovação, treinamento, redes e investimentos de capital estrangeiro. São identificados três grupos de empresas — segundo o nível educacional, técnico e profissiona- e se encontraram diferenças significativas entre esses grupos em relação aos indicadores analisados. Em geral, existe uma baixa proporção de profissionais e técnicos nas indústrias de manufatura colombianas estudadas, apesar de existirem mais profissionais do que técnicos. O principal resultado é que os resultados da inovação,conectividade com redes externas, os esforços de treinamento e os investimentos em atividades de inovação e de capital estrangeiro, são maiores no conglomerado de profissionais.

Palavras-chave. Inovação; capital humano; treinamento; redes; investimento estrangeiro. 


\section{Introducción}

En los países en desarrollo muchos de los procesos de innovación se dan principalmente a través de transferencias de tecnologías (Rosenberg, 2002). De acuerdo con Cassiolato \& Lastres (1999), en la mayoría de los países en desarrollo el método tradicional de transferencia de tecnología se da a través de subsidiarias de multinacionales o por la importación de plantas diseñadas, construidas e implantadas por los contratantes extranjeros. Sin embargo, estos procesos a menudo no generan una acumulación tecnológica en el país receptor (Freeman, 1987) debido a su bajo nivel de capital humano (Lucas, 1990) que no está preparado para asimilar las nuevas tecnologías. Los procesos innovadores no se generan con la sola adquisición de productos nuevos sino que se requiere de una capacidad de absorción para apropiar y desarrollar nuevos conocimientos. Dado que la capacidad de absorción de una firma está en función de la capacidad de absorción de conocimiento y habilidades de los empleados que laboran en ella (Cohen \& Levinthal, 1990), el conocimiento y destrezas previas de los empleados se vuelven factores cruciales en los procesos innovadores.

Según Cohen \& Levinthal (1990), la capacidad de absorción de una firma es la capacidad de su gente para reconocer, asimilar y aplicar el valor de información externa novedosa, lo cual, a su vez, está en función del nivel previo de la firma relacionado al conocimiento, experiencia previa y diversidad de experticia. En otras palabras, la capacidad de absorción de una firma está en función de su capital humano. Los empleados con las mejores habilidades son los que efectivamente contribuyen a implementar innovaciones (Link \& Siegel, 2007). Sin embargo, el capital humano de las empresas en países en desarrollo no siempre tiene el nivel requerido para asimilar nuevas tecnologías y desarrollar procesos innovadores. Alcorta \& Peres (1998) mostraron cómo el bajo desempeño en innovación de los países latino-americanos estaba claramente relacionado con una pobre inversión en capital humano.

En este artículo se argumenta que una organización puede aumentar su capacidad innovadora a partir del capital humano de sus miembros y de la infraestructura de soporte con que cuenten para actividades de innovación. En la literatura se sugieren al menos cuatro formas de mejorar la capacidad de absorción de nuevas tecnologías en una firma a partir de su capital humano, a saber: asegurando un nivel educativo terciario (educación superior) en el personal (OECD, 2007); entrenando al personal con programas de entrenamiento técnico avanzado (Cohen \& Levinthal, 1990); fomentando la creación de vínculos de red con otras compañías del sector de la firma que permitan la creación de comunidades de práctica donde se fomente el aprendizaje y la innovación entre sus miembros (Brown \& Duguid, 1991; McEvily \& Marcus, 2005), invirtiendo en actividades de innovación; y finalmente, atrayendo inversión de capital privado extranjero como una forma de incentivar la diseminación y producción de conocimiento e innovación tecnológica (Ciruelos \& Wang, 2005).

El propósito de este artículo es analizar, a partir de la Segunda Encuesta de Desarrollo en Innovación Tecnológica realizada en Colombia en el 2005, ${ }^{4}$ la relación entre el capital humano en las industrias manufactureras colombianas y cinco factores asociados con la innovación (resultados de innovación, esfuerzos de capacitación, inversiones en actividades de innovación, vínculos con 4 Encuesta realizada por el DANE, el DNP y Colciencias. 
redes externas e inversión de capital social privado extranjero). El análisis de la Encuesta es apropiado, pues su metodología incluye el análisis de clúster por capital humano para identificar si existen conglomerados en las empresas manufactureras colombianas debido a esta variable; a la vez que realiza análisis de varianza (ANOva) entre conglomerados para evaluar las diferencias significativas entre cada conglomerado y los factores asociados con la innovación estudiados. Finalmente, para asegurar la nitidez de estos análisis y evitar distorsiones por tamaño de empresa, la encuesta se dividió en cuatro grandes segmentos: micro, pequeñas, medianas y grandes empresas. La definición de conglomerados y los análisis de clúster de capital humano se realizaron para cada segmento.

En este artículo se elaboran argumentos que relacionan el capital humano con diferentes factores de innovación a partir de la literatura enfocada en entender los determinantes de la innovación en las organizaciones. Estos factores incluyen los procesos innovadores, las comunidades de conocimiento, la inversión en innovación, la generación de conocimiento, los procesos cognitivos y la capacidad de absorción.

El artículo está organizado en cuatro secciones. En la primera se presenta el marco teórico sobre innovación, los factores que inciden en la innovación y se desarrollan las hipótesis del estudio. En la segunda se describe la muestra, las variables de estudio y el método utilizado para la creación de los clústeres de capital humano dentro de cada segmento de empresas. En la tercera sección se presentan los resultados de los análisis de clúster y ANOVAS con relación a las hipótesis formuladas. Finalmente, en la cuarta sección se incluyen las principales conclusiones del estudio, sus limitaciones y sugerencias de investigación futura.

\section{Marco teórico}

Las organizaciones se basan en actividades humanas para desarrollar sus productos y servicios (Fox, 2008). En consecuencia, la calidad de los productos y servicios, y por ende, la capacidad de la organización para lograr una ventaja competitiva, depende en buena parte del conocimiento y habilidades de sus empleados, es decir, su capital humano (Coleman, 1988; Metcalfe, 2006). De acuerdo con Link \& Siegel (2007), los empleados con las mejores habilidades son los que pueden contribuir de una manera efectiva a implementar procesos innovadores.

Para explicar la relación entre factores individuales y la innovación, las teorías de aprendizaje y cognición organizacional (Argyris \& Schon, 1978; Nonaka, 1994; Nonaka \& Takeuchi, 1995) se enfocan en los procesos de aprendizaje y generación de conocimiento en las organizaciones (Lam, 2005). Igualmente, otros autores (Hatch \& Dyer, 2004) argumentan que el capital humano específico de una firma es un recurso fundamental para la generación de conocimiento a través del aprendizaje.

Finalmente, Cohen \& Levinthal (1990) sostienen que la capacidad de absorción de una firma es la colección de las capacidades individuales de sus empleados para reconocer, asimilar y aplicar el valor de información externa novedosa. En otras palabras, la capacidad de absorción de una firma está en función de su capital humano.

\subsection{De las capacidades individuales a la innovación en las organizaciones}

Schumpeter (1947) define la innovación como la introducción de nuevas combinaciones de factores de producción. En un sentido más amplio, la innovación puede entenderse como el conjunto de actividades orientadas a implementar nuevos productos o procesos o a realizar mejoramientos en los mismos 
(Langebaek \& Vásquez, 2007). La innovación se puede identificar a partir de tres factores: el proceso de innovación (actividades de innovación), los resultados de innovación (producto) y el grado al cual la innovación es una novedad (aporte incremental) (Boer \& During, 2001).

Por otro lado, la capacidad innovadora de una organización está asociada con su competitividad (McEvily \& Marcus, 2005). Según Prahalad \& Hamel (1990), las raíces de la competitividad en las organizaciones están en la creación de competencias centrales, las cuales reflejan el aprendizaje colectivo de la organización con respecto a la forma en que coordina las diversas destrezas de producción y cómo integra sus líneas tecnológicas. Las organizaciones crean sus competencias centrales a partir de las capacidades individuales de sus miembros (Hayes, Pisano \& Upton, 1996; Williams, 1994).

Desde la perspectiva basada en los recursos, la formulación estratégica se centra en el análisis interno de la organización en busca de fortalezas para lograr ventajas competitivas (Sanabria, 2005). Según Teece, Pisano \& Shuen (1997), esta perspectiva invita a considerar asuntos como la adquisición de destrezas y el aprendizaje como factores estratégicos fundamentales. En este sentido, el capital humano es considerado como uno de los recursos intangibles más importantes en la búsqueda de ventajas competitivas para la organización (Sanabria, 2005), debido a su carácter idiosincrásico y porque es el recurso con el cual se desarrollan las capacidades distintivas de la organización.

Finalmente, de acuerdo con Coleman (1988) el capital humano se crea por los cambios en las personas sobre destrezas y capacidades que los hacen capaces de actuar en formas nuevas.

En este artículo se analizan factores de innovación que están asociados con aspectos que conforman en el capital humano en las organizaciones.

\subsection{El capital humano en los factores y resul- tados de innovación}

El capital humano representa el conocimiento, las capacidades individuales y la experiencia que tiene la gente (Becker, 1964; Coleman, 1988) y, en las industrias, ha sido considerado como uno de los indicadores de entrada a los procesos de innovación (Brusoni, Cefis \& Orsenigo, 2006). De acuerdo con la literatura, la innovación como un actividad intensiva en conocimiento se beneficia del capital humano porque las personas mejor educadas son las que cuentan con más experiencia e invierten más tiempo, energía y recursos en perfeccionar sus destrezas, lo cual beneficia de forma directa a la organización en sus procesos de innovación (Dakhli \& DeClercq, 2004).

La capacidad innovadora de una organización tiene más probabilidad de incrementarse cuando la organización ha logrado desarrollar un capital humano elevado que está en condiciones de absorber nuevos conocimientos y tecnologías. A su vez, la capacidad de absorción de una organización está en función de su nivel previo de conocimientos y experiencia (Cohen \& Levinthal, 1990), lo cual se conforma del conocimiento, experiencia y capacidades individuales de sus miembros.

Según Becker (1964) las personas con un capital humano superior perciben una mayor variedad de oportunidades que los demás. Las nuevas ideas y comportamientos innovadores provienen de los individuos que están envueltos en la dinámica de creación de conocimiento; y surgen de la interiorización del conocimiento tácito a través del aprendizaje que se da en la solución cotidiana de problemas durante las actividades de la organización (Arrow, 1962). En este proceso, 
la formación previa y su constante actualización y entrenamiento, crean las condiciones básicas para que este proceso sea innovador.

El capital humano en una organización se reconoce, entre otros aspectos, por el conocimiento y experiencia de sus miembros, que se construye a partir del nivel de educación académica y el entrenamiento que hayan recibido (Dakhli \& DeClercq, 2004). Además, el capital humano se enriquece por factores asociados con la innovación tales como las redes, en las que se dan aprendizajes mutuos entre los miembros dentro y fuera de la organización (Brown \& Duguid, 1991; Colombo, 2003) y como los beneficios de adquisición tecnológica derivados de la inversión de capital extranjero (Shu \& Teixeira, 2010; Tavares \& Teixeira, 2005). Todo lo anterior favorece los procesos innovadores en las organizaciones porque amplía sus conocimientos tecnológicos y su capacidad de reconocimiento de nuevas oportunidades. A continuación se detallan cada uno de estos:

\section{Nivel educativo}

Según Becker (1964), uno de los principales factores que constituyen el capital humano en una organización es la educación académica de los empleados, ya que las capacidades individuales están asociadas al conocimiento interiorizado de un individuo adquirido a partir de su experiencia y los procesos formativos que haya tenido.

De esta manera, se espera que una organización que cuente con empleados bien preparados, esto es, con un nivel de educación alto, tenga mayor capacidad de absorción tecnológica porque sus empleados están en condiciones de asimilar nuevos conocimientos y de aplicarlos en procesos innovadores. De acuerdo con lo anterior se plantean la siguiente hipótesis:
Hipótesis 1 (H1). El nivel educativo de los empleados en una empresa manufacturera se asocia positivamente con los resultados de innovación.

\section{Esfuerzos de capacitación}

Una forma de crear capacidades previas para la innovación a parir del capital humano, es asegurar un nivel de destrezas especializadas y significativas para la organización. Como lo sustenta Becker (1964), uno de los factores que constituyen el capital humano es el aprendizaje práctico que reciben los empleados a partir de procesos de entrenamiento. Igualmente, la literatura ha mostrado que la inversión continua de una organización en entrenamiento aumenta la probabilidad de innovación de la firma (Bauernschuster, Falck \& Heblich, 2009).

Cohen \& Levinthal (1990) manifiestan que una forma en que las firmas invierten en su capacidad de absorción es enviando a su personal a programas de entrenamiento técnico avanzado. De esta manera, la organización contará con empleados capacitados para asimilar nuevas tecnologías a partir de las cuales puede generar procesos y productos innovadores. Sin embargo, el entrenamiento especializado, por lo general, requiere que las personas cuenten con conocimientos y destrezas previas avanzadas para poder estar en capacidad de asimilarlo y aplicarlo.

Por otro lado, la noción de competencias centrales (Prahalad \& Hamel, 1990) implica que las actividades de aprendizaje y creación de conocimiento de las firmas tienden a ser acumulativas y dependen de su recorrido previo. Esto significa que es más probable que las personas con un alto nivel de educación sean más propensas a recibir entrenamiento avanzado que las demás, ya que las organizaciones preferirán invertir en los empleados que puedan aprovechar a 
cabalidad capacitaciones especializadas que tienden a ser costosas. De acuerdo con esto, se plantea la siguiente hipótesis:

Hipótesis 2 (н2). El nivel educativo de los empleados de una empresa manufacturera se relaciona positivamente con la inversión en capacitación tecnológica.

\section{Redes externas}

Las actividades de aprendizaje y difusión del conocimiento se dan en contexto sociales (Lam, 2005) y la capacidad innovadora de una empresa aumenta en la medida que los individuos cuenten con oportunidades para relacionarse con profesionales de formación similar en otras compañías del sector.

La interacción social es fundamental para el aprendizaje y la creación de conocimiento en las organizaciones (Brown \& Duguid, 1991, 1998; Lam, 2005; Nonaka, 1994). De acuerdo con Brown \& Duguid (1991) una fuente de innovación reside en la interface entre una organización y su entorno. La capacidad de absorción de una firma depende de la transferencia de conocimiento a través y entre subunidades (Cohen \& Levinthal, 1990).

Los vínculos de red entre las organizaciones permiten la creación de comunidades de práctica (Brown \& Duguid, 1991; Wenger, 1998) donde se fomenta el aprendizaje mutuo. La práctica en experiencias de trabajo compartidas provee una actividad social en la cual las perspectivas compartidas y los repertorios cognitivos se desarrollan para facilitar el compartir y la transmisión del conocimiento (Lam, 2005).

De acuerdo con Powell \& Grodal (2005), a través de las redes se crean proyectos de cooperación científica donde se presentan esquemas de colaboración que fomentan el aprendizaje. Para estos autores, las redes inter-organizacionales son los medios a tra- vés de los cuales las organizaciones pueden jalar o intercambiar recursos y conjuntamente desarrollar nuevas ideas y destrezas, lo cual tiene una influencia positiva en la innovación. Es así como las comunidades de práctica a través de las redes juegan un papel muy importante en la explotación de capacidades innovadoras.

Pero crear redes con otras organizaciones y formar comunidades de práctica en temas tecnológicos avanzados requiere de conocimientos y destrezas especializadas, esto es, un capital humano altamente desarrollado. En las firmas se da aprendizaje mutuo en la medida en que estén mejor capacitadas para absorber la tecnología del otro (Colombo, 2003); es decir, sólo las organizaciones que cuenten con un alto nivel de capital humano tienen mayores posibilidades de crear y beneficiarse de redes externas en sus procesos innovadores. De esta manera, los empleados con un alto nivel de formación académica están mejor dotados para relacionarse con miembros especializados del sector y generar espacios de discusión de nivel técnico avanzado de los que pueden surgir ideas innovadoras. Según esto, se plantea que:

Hipótesis 3 (н3). El nivel educativo de los empleados de una empresa manufacturera se asocia positivamente con el reconocimiento de más fuentes externas de innovación.

\section{Inversión en actividades de innovación}

La asignación de recursos para la innovación es un factor crítico para la sostenibilidad de las empresas (Fox, 2008). Uno de los factores que más tradicionalmente ha estado asociado con las actividades de innovación en las empresas es la inversión en investigación y desarrollo (Veryzer, 2005). Este tipo de inversión se conoce como inversión en intangibles que complementan la inversión en activos físicos. Según Alcorta \& Peres (1998), 
este tipo de inversión incluye, además de la inversión en investigación y desarrollo, las inversiones en técnicas gerenciales y sistemas de soporte que en conjunto son las que permiten la acumulación de conocimiento en las organizaciones. Dicho esto, es más factible que una empresa invierta en sistemas de apoyo a la innovación si cuenta con personal calificado que pueda comprenderlos y usarlos en los procesos innovadores. Por lo tanto, se plantea:

Hipótesis 4 (H4). El nivel educativo de los empleados de una empresa manufacturera, se relaciona positivamente con la inversión en actividades de innovación.

\section{Inversión de capital privado extranjero}

Uno de los factores de innovación estudiados en la literatura se refiere a la inversión de capital privado extranjero con la idea que genera mejoras en la capacidad tecnológica del país receptor (Cassiolato \& Lastres, 1999). Al respecto, la investigación empírica ha mostrado que el capital extranjero tiene efectos directos e indirectos en el capital humano del país receptor (Shu \& Teixeira, 2010; Tavares \& Teixeira, 2005).

La inversión de capital extranjero también juega un rol importante en la diseminación y producción del conocimiento y la innovación tecnológica (Ciruelos \& Wang, 2005). En Colombia, la investigación ha mostrado que la participación de capital extranjero aumenta la inversión en innovación en las industrias (Langebaek \& Vásquez, 2007). Adicionalmente, la inversión de capital extranjero se atrae en la medida que las industrias cuenten con proyectos tecnológicamente avanzados, que son los que requieren una mayor interacción con el sistema, lo cual a su vez, tiene un impacto positivo en las actividades innovadoras (Shu \& Teixeira, 2010). Esto es posible porque los inversionistas extranjeros van a ver más posibilidad de retornos positivos a su inversión en compañías que estén desarrollando proyectos de innovación tecnológica, ya que de esta manera demuestran que tienen gente trabajando en innovación y que tienen un camino recorrido en el proceso. Es por esto que es más probable que las industrias que cuenten con personal altamente calificado sean las que más se involucren en procesos de innovación tecnológica, dado que este personal tiene los conocimientos y capacidades requeridas y por tanto, son industrias más propensas a recibir inversión de capital privado extranjero. De acuerdo con lo anterior, se propone que:

Hipótesis 5 (H5). El nivel educativo de los empleados de una empresa manufacturera, se relaciona positivamente con la inversión de capital extranjero para invertir en actividades de innovación.

\section{Metodología}

El estudio utilizó la base de datos de la Segunda Encuesta de Desarrollo e Innovación Tecnológica. Esta encuesta fue realizada en el 2005 a empresas manufactureras en Colombia para identificar la dinámica de desarrollo tecnológico a partir de la intensidad y trayectoria de las actividades de innovación y desarrollo tecnológico. La base consta de 6.670 registros, de los cuales, debido a información incompleta o datos relevantes faltantes, se excluyeron 458 casos, quedando 6.212 en total para los análisis de este estudio. A continuación se describen las variables empleadas para las pruebas de hipótesis.

\section{Variables}

Corresponden a indicadores elaborados a partir de campos de la encuesta relacionados con los aspectos a estudiar: capital humano, resultados de innovación, vínculos con 
redes externas, esfuerzos de inversión en capacitación y actividades tecnológicas, e inversión de capital social privado extranjero.

Capital humano. El capital humano ha sido medido en las investigaciones a partir del nivel educativo y la experiencia laboral (Dakhli \& DeClercq, 2004). Para este estudio se toma como proxy de capital humano el nivel educativo de los empleados en las empresas industriales ya que la encuesta no ofrece suficiente información para identificar la experiencia. Se definen entonces tres categorías: proporción de profesionales o más, que incluye el porcentaje de empleados que tienen una profesión y estudios posteriores con relación a todo el personal ocupado de la empresa; proporción de técnicos, que representa el porcentaje de empleados con formación técnica incluyendo la capacitación dada por el SENA; ${ }^{5}$ y proporción de personal con bajo nivel de educación que recoge el porcentaje de empleados que no tiene formación profesional ni técnica.

Resultados de Innovación. Los resultados de innovación se miden a partir del número de resultados de innovación que comprende la suma de todos los resultados de innovación reportados como objetivos obtenidos por las empresas, dividida por personal ocupado. Estos resultados incluyen innovaciones de producto, mercado, en procesos, materiales y de gestión.

Esfuerzos de capacitación. Se mide por el monto total invertido en capacitación por persona durante el período 2003 y 2004.

Vínculo con redes externas. Para ver el grado de conectividad de la empresa con redes

5 El sena (Servicio Nacional de Aprendizaje) es un instituto de formación técnica y tecnológica creado por el Estado colombiano como una forma de ayudar a los trabajadores, ofreciendo y ejecutando la formación profesional integral para la incorporación de las personas en actividades productivas que contribuyan al crecimiento social, económico y tecnológico del país (http://www. sena.edu.co). externas de innovación, se tiene en cuenta la variable número de fuentes externas, que representa la suma de todas las fuentes externas reconocidas en el proceso innovador por personal ocupado.

Inversión en actividades de innovación. Esta variable recoge la inversión en actividades de innovación tales como sistemas de gestión de calidad, en producción de bienes y servicios, en gestión ambiental, en tecnologías de administración y en proyectos de investigación y desarrollo. Esta variable se calcula con el promedio de inversión total en actividades de innovación por persona durante los años 2003 y 2004.

Capital extranjero. Indica la proporción de capital social privado extranjero que tiene una empresa con relación a su patrimonio.

Finalmente, se crearon variables dummy para indicar la presencia o no de resultados de innovación, reconocimiento de fuentes externas, inversión en capacitación, inversión en actividades de innovación y si la empresa tiene capital privado extranjero.

\section{Clusterización}

La investigación sobre innovación en países en desarrollo ha mostrado que, aunque las firmas innovadoras tienen comparativamente un alto número de técnicos calificados, en general la proporción de personal calificado es bajo, particularmente en las empresas pequeñas y medianas (Arocena \& Sutz, 2002). Thornhill (2006) argumenta que mientras que las firmas de alta tecnología usualmente mantienen un nivel mínimo de personal técnico altamente calificado y apto técnicamente para sostenerse en la competencia tecnológica, en los sectores de baja tecnología generalmente se cuenta con una fuerza de trabajo con entrenamiento más instrumental que está dispuesta a aprender. En este sentido, Colombia es un país en desarrollo en el que la industria manufactu- 
rera representa el 15\% del PIB nacional, cifra que no ha aumentado en la última década (DANE, 2008). Dado que este estudio se basa en información sobre industrias manufactureras en un país en desarrollo, resulta de interés ver la incidencia del nivel de educación en los resultados y procesos de innovación.

Con el objeto de analizar la relación entre la formación académica y los resultados de interés, se clasificaron las empresas en conglomerados, usando como variables de aglomeración las relacionadas con el nivel educativo. Para la determinación del número de conglomerados se realizó inicialmente una clasificación jerárquica utilizando el método de vinculación inter-grupos a partir de la medida de distancia euclidiana. Se encontró que en todas las muestras el número más apropiado de conglomerados es 3 . A partir de este número, se agruparon los casos por el método de clusterización de K-medias tomando como variable de diferenciación el grado de formación de los empleados (se explica en el siguiente párrafo). Este procedimiento intenta identificar grupos relativamente homogéneos de casos con base en las características seleccionadas se uso el programa SPSS v. 14.

Las variables utilizadas (indicadores) para la creación de los conglomerados fueron la proporción de profesionales o más (que incluye profesionales y personas con estudios de postgrado), la proporción de técnicos (que abarca los empleados con formación técnica tipo SENa) y la proporción de personal con bajo nivel de educación (que representa a los empleados que no cuentan con ninguno de los grados anteriores). La escogencia de estas tres variables obedece al interés de examinar la relación y aspectos diferenciadores entre el conocimiento formal, y el entrenamiento y práctica en actividades técnicas. Estos dos aspectos son clave en la relación entre capital humano e innovación.

\section{Resultados}

La base consta de 6.212 empresas manufactureras. Para este estudio se segmentó según tamaño de empresa (micro, pequeña, mediana y grande), ${ }^{6}$ obteniéndose cuatro segmentos así: microempresas (816), pequeñas (3.241), medianas (1.569) y grandes (586 casos) (ver Tabla 1). A continuación se presentan los estadísticos descriptivos para cada segmento (tamaño de empresa).

El segmento de las microempresas indica un muy bajo nivel de educación de sus empleados (ver Tabla 2), en donde no cuentan con personas con doctorado (Ph.D.), solo el $16 \%$ de los empleados son profesionales y no se aprecia un porcentaje importante

6 Esta segmentación se realizó teniendo en cuenta los criterios de clasificación de empresas establecidos en la Ley 905 de 2004 del Congreso de Colombia [disponible en http://www.secretariasenado.gov.co/senado/basedoc/ ley/200o/ley_0590_200o.html], según la cual microempresas son las que tienen de o a 9 empleados, pequeñas de 10 a 49, medianas de 50 a 199 y con más de 200 empleados se consideran grandes.

Tabla 1. Descriptivos por tamaño de empresa

\begin{tabular}{lcc}
\hline Tamaño de empresa & Número de casos & Porcentaje \\
\hline Micro & 816 & $13,1 \%$ \\
Pequeña & 3.241 & $52,2 \%$ \\
Mediana & 1.569 & $25,3 \%$ \\
Grande & 586 & $9,4 \%$ \\
\hline Total & 6.212 & $100,0 \%$ \\
\hline
\end{tabular}


Tabla 2. Estadísticos descriptivos de las microempresas

\begin{tabular}{|c|c|c|c|c|c|}
\hline & Frecuencia & Porcentaje & Validos & Perdidos & \\
\hline $\begin{array}{l}\text { Inversión en capacitación 2003-2004 (Sí/ } \\
\text { No) }\end{array}$ & 227 & $28 \%$ & 812 & 9 & \\
\hline $\begin{array}{l}\text { Inversión en actividades de innovación } \\
\text { 2003-2004 (Sí/No) }\end{array}$ & 192 & $23 \%$ & 381 & $\mathrm{o}$ & \\
\hline $\begin{array}{l}\text { Reconocimiento de fuentes externas (Sí/ } \\
\text { No) }\end{array}$ & 244 & $30 \%$ & 821 & 0 & \\
\hline \multirow[t]{2}{*}{ Resultados de innovación (Sí/No) } & 241 & $62 \%$ & 387 & (434) & \\
\hline & Mínimo & Máximo & Media & Desv. Típ. & $\mathrm{N}$ \\
\hline Años promedio de educación & 5 & 18 & 10,87 & 2,44 & 816 \\
\hline Número de Doctores (Ph.D.) & o & 1 & 0,00 & 0,07 & 821 \\
\hline Número de profesionales o más & o & 7 & 0,96 & 1,06 & 821 \\
\hline Número de técnicos Sena & $\mathrm{o}$ & 8 & 0,72 & 1,33 & 821 \\
\hline Porcentaje profesionales o más & $\mathrm{o}$ & 1 & 0,16 & 0,19 & 816 \\
\hline Porcentaje técnicos Sena & $\mathrm{o}$ & 1 & 0,11 & 0,19 & 816 \\
\hline $\begin{array}{l}\text { Capacitación monto total } 2003 \text { y } 2004 \\
\text { por personal ocupado* }\end{array}$ & o & 17.900 & 93,14 & 694,90 & 807 \\
\hline $\begin{array}{l}\text { Inversión en actividades en innovación } \\
\text { por personal ocupado* }\end{array}$ & o & 174.220 & $1.417,78$ & $9 \cdot 937,47$ & 816 \\
\hline Número de fuentes externas reconocidas & o & 18 & 1,36 & 3,54 & 821 \\
\hline Número de resultados de innovación & o & 70 & 4,87 & 9,62 & 387 \\
\hline
\end{tabular}

Nota. ${ }^{\star}$ Las cifras de capacitación monto por personal ocupado e inversión actividades en innovación por personal ocupado están en miles de pesos colombianos.

de técnicos (11\%). En este segmento, el 62\% de las empresas presenta resultados de innovación, el $28 \%$ invierte en capacitación (tomando como referencia 2003 y 2004 , con un promedio de inversión de $\$ 93.000$ por empleado), el 23\% invierte en actividades de innovación (con un promedio de inversión de cop $\$ 1.418 .000$ por empleado) y el $30 \%$ refleja vínculos con redes externas a través del reconocimiento de fuentes externas para las ideas de innovación. Este último resultado llama la atención dado el bajo nivel de formación académica de los empleados, lo cual induce a pensar que es probable que esto se deba a contactos con universidades e instituciones públicas en busca de apoyo.

\subsection{Pequeñas empresas}

El segmento de empresas pequeñas (3.241 casos) se caracteriza por una proporción de profesionales y técnicos similar al de las microempresas (14\% y $11 \%$, respectivamente) (ver Tabla 3). En este segmento hay alguna presencia de Doctores (Ph.D.), pero muy poco significativa $(0,02$ en promedio por empresa); es decir, en términos de nivel de educación, las empresas pequeñas parecen no diferenciarse de las microempresas. En cuanto a los demás indicadores, el $76 \%$ de las pequeñas empresas presenta resultados de innovación (14 puntos porcentuales más que las microempresas), el $48 \%$ invierte en capacitación (con un promedio de COP $\$ 137.540$ por empleado), el $41 \%$ invierte en actividades 
Tabla 3. Estadísticos descriptivos de las pequeñas empresas

\begin{tabular}{|c|c|c|c|c|c|}
\hline & Frecuencia & Porcentaje & Validos & Perdidos & \\
\hline $\begin{array}{l}\text { Inversión en capacitación 2003-2004 } \\
\text { (Sí/No) }\end{array}$ & 1.567 & $48 \%$ & 3.229 & 12 & \\
\hline $\begin{array}{l}\text { Inversión en actividades de inno- } \\
\text { vación 2003-2004 (Sí/No) }\end{array}$ & 1.328 & $41 \%$ & 3.240 & 1 & \\
\hline $\begin{array}{l}\text { Reconocimiento de fuentes externas } \\
\text { (Sí/No) }\end{array}$ & 1.471 & $45 \%$ & 3.241 & o & \\
\hline \multirow[t]{2}{*}{ Resultados de innovación (Sí/No) } & 1.681 & $76 \%$ & 2.204 & 1.037 & \\
\hline & Mínimo & Máximo & Media & Desv. Típ, & $\mathrm{N}$ \\
\hline Años promedio de educación & 5 & 17 & 10,73 & 2,11 & 3.241 \\
\hline Número de Doctores (Ph.D.) & $\mathrm{o}$ & 6 & 0,02 & 0,23 & 3.241 \\
\hline Número de profesionales o más & o & 27 & 3,19 & 3,13 & 3.241 \\
\hline Número de técnicos Sena & $\mathrm{o}$ & 43 & 2,56 & 4,32 & 3.241 \\
\hline Porcentaje profesionales o más & o & 1 & 0,14 & 0,12 & 3.241 \\
\hline Porcentaje técnicos Sena & o & 1 & 0,11 & 0,17 & 3.241 \\
\hline $\begin{array}{l}\text { Capacitación monto total } 2003 \text { y } 2004 \\
\text { por personal ocupado* }\end{array}$ & o & 56.775 & 137,54 & $1.190,38$ & 3.228 \\
\hline $\begin{array}{l}\text { Inversión en actividades en inno- } \\
\text { vación por personal ocupado* }\end{array}$ & o & 177.812 & $1.079,41$ & $5 \cdot 369,21$ & 3.240 \\
\hline $\begin{array}{l}\text { Número de fuentes externas recono- } \\
\text { cidas }\end{array}$ & o & 18 & 2,38 & 4,34 & 3.241 \\
\hline Número de resultados de innovación & o & 145 & 8,31 & 13,97 & 2.204 \\
\hline
\end{tabular}

Nota. ${ }^{\star}$ Las cifras de capacitación monto por personal ocupado e inversión actividades en innovación por personal ocupado están en miles de pesos colombianos.

de innovación (COP\$1.079.410 en promedio) y el $45 \%$ reconoce fuentes externas de ideas en innovación. Este segmento invierte más en capacitación en comparación con las microempresas, pero menos en actividades de innovación por personal ocupado.

\subsection{Medianas}

La proporción de profesionales y técnicos se mantiene similar en las empresas medianas con respecto a las pequeñas y las microempresas ( $13 \%$ y $10 \%$, respectivamente), es decir, el nivel de educación de los empleados no aumenta en las empresas medianas (ver Tabla 4). Se aprecia un mayor número de Ph.D. (99) aunque representa una cifra muy pequeña con relación al número de empresas (o,31 en promedio). Este segmento muestra 4 puntos porcentuales más en los resultados de innovación que las empresas pequeñas y 18 puntos porcentuales más que las microempresas. El $69 \%$ invierte en capacitación (con COP $\$ 168.740$ por empleado en promedio), el $60 \%$ invierte en actividades de innovación (correspondiendo a COP\$1.251.810 por empleado) y el 59\% reconoce fuentes externas de innovación.

\subsection{Grandes}

El segmento de las empresas grandes cuenta con 586 casos y muestra esfuerzos más altos 
Tabla 4. Estadísticos descriptivos de las medianas empresas

\begin{tabular}{|c|c|c|c|c|c|}
\hline & Frecuencia & Porcentaje & Validos & Perdidos & \\
\hline $\begin{array}{l}\text { Inversión en capacitación 2003-2004 } \\
\text { (Sí/No) }\end{array}$ & 1.072 & $69 \%$ & 1.562 & 7 & \\
\hline $\begin{array}{l}\text { Inversión en actividades de inno- } \\
\text { vación 2003-2004 (Sí/No) }\end{array}$ & 934 & $60 \%$ & 1.567 & 2 & \\
\hline $\begin{array}{l}\text { Reconocimiento de fuentes externas } \\
\text { (Sí/No) }\end{array}$ & 925 & $59 \%$ & 1.569 & o & \\
\hline \multirow[t]{2}{*}{ Resultados de innovación (Sí/No) } & 979 & $80 \%$ & 1.218 & 351 & \\
\hline & Mínimo & Máximo & Media & Desv. Típ, & $\mathrm{N}$ \\
\hline Años promedio de educación & o & 38 & 10,80 & 2,46 & 1.569 \\
\hline Número de Doctores (Ph.D.) & o & 99 & 0,31 & 5,00 & 1.569 \\
\hline Número de profesionales o más & o & 121 & 12,68 & 14,57 & 1.569 \\
\hline Número de técnicos Sena & o & 153 & 9,75 & 14,00 & 1.569 \\
\hline Porcentaje profesionales o más & o & 1 & 0,13 & 0,13 & 1.569 \\
\hline Porcentaje técnicos Sena & o & 1 & 0,10 & 0,13 & 1.569 \\
\hline $\begin{array}{l}\text { Capacitación monto total } 2003 \text { y } \\
2004 \text { por personal ocupado* }\end{array}$ & o & 20.280 & 168,74 & 799,39 & 1.562 \\
\hline $\begin{array}{l}\text { Inversión en actividades en inno- } \\
\text { vación por personal ocupado* }\end{array}$ & o & 188.105 & $1.250,81$ & $6.441,97$ & 1.567 \\
\hline $\begin{array}{l}\text { Número de fuentes externas recono- } \\
\text { cidas }\end{array}$ & o & 18 & 3,27 & 4,76 & 1.569 \\
\hline Número de resultados de innovación & $\mathrm{o}$ & 140 & 11,23 & 17,48 & 1.218 \\
\hline
\end{tabular}

Nota. ${ }^{\star}$ Las cifras de capacitación monto por personal ocupado e inversión actividades en innovación por personal ocupado están en miles de pesos colombianos.

de inversión en capacitación y actividades tecnológicas ( $82 \%$ y $78 \%$, respectivamente) que los demás segmentos (ver Tabla 5). También refleja más resultados de innovación (86\%) y un mayor porcentaje de reconocimiento de fuentes externas ( $72 \%)$. Sin embargo, la proporción de profesionales y técnicos no aumenta significativamente con relación a los demás segmentos de empresa ( $15 \%$ y $11 \%$, respectivamente) e incluso el promedio de $\mathrm{Ph} . \mathrm{D}$. es menor que para las empresas medianas (o,27 por empresa). Este dato llama la atención pues se esperaría que las empresas grandes no sólo le den más importancia al factor de educación como forma de asegurar su competitividad tecnológica, sino que cuenten con los recursos para vincular personal de este nivel. El promedio de inversión en capacitación es de COP\$266.150 por empleado y el promedio de inversión en actividades de innovación es de COP\$2.262.66o por empleado, resultado que duplica el promedio de inversión por estos mismos conceptos en los demás segmentos.

\subsection{Análisis comparativo}

En general, se aprecia que a medida que aumenta el tamaño de la empresa, aumentan todos los indicadores relacionados con el capital humano y la innovación (ver Tabla 6); es decir, aumentan los resultados de innovación, el nivel educativo del personal, la inversión en capacitación y de capital 
Tabla 5. Estadísticos descriptivos de las grandes empresas

\begin{tabular}{lccccc}
\hline & Frecuencia & Porcentaje & Validos & Perdidos & \\
\hline Inversión en capacitación 2003-2004 (Sí/ & & & & & \\
No) & 481 & $82 \%$ & 584 & 2 & \\
Inversión en actividades de innovación & & & & & \\
2003-2004 (Sí/No) & 458 & $78 \%$ & 586 & 0 & \\
Reconocimiento de fuentes externas (Sí/ & & & & & \\
No) & 422 & $72 \%$ & 586 & 0 & \\
Resultados de innovación (Sí/No) & 432 & $86 \%$ & 499 & 87 & \\
\hline & Mínimo & Máximo & Media & Desv. Típ, & N \\
\hline Años promedio de educación & 5 & 17 & 11,23 & 1,80 & 586 \\
Número de Doctores (Ph.D.) & 0 & 32 & 0,27 & 1,71 & 586 \\
Número de profesionales o más & 0 & 3.081 & 86,05 & 174,10 & 586 \\
Número de técnicos Sena & 0 & 2.976 & 68,96 & 192,40 & 586 \\
Porcentaje profesionales o más & 0 & 1 & 0,15 & 0,14 & 586 \\
Porcentaje técnicos Sena & 0 & 1 & 0,11 & 0,12 & 586 \\
Capacitación monto total 2003 y 2004 por & & & & & \\
personal ocupado* & 0 & 9.901 & 266,15 & 694,22 & 584 \\
Inversión en actividades en innovación & & & & & \\
por personal ocupado* & 0 & 99.719 & $2.262,66$ & $7.794,01$ & 586 \\
Número de fuentes externas reconocidas & 0 & 18 & 4,65 & 5,31 & 586 \\
\hline Número de resultados de innovación & 0 & 168 & 18,25 & 25,08 & 4.499 \\
\hline
\end{tabular}

Nota. ${ }^{\star}$ Las cifras de capacitación monto por personal ocupado e inversión actividades en innovación por personal ocupado están en miles de pesos colombianos.

extranjero en actividades de innovación, de innovación mantiene una proporción así como la conectividad con redes externas. de uno a diez en todos los segmentos. Esto En cuanto al nivel de educación, se observa es, por cada peso que se invierte en capaque aunque el número de profesionales citación por empleado, se invierten diez en y técnicos aumenta visiblemente para las actividades de innovación. Las actividades empresas grandes, la proporción con re- de innovación incluyen las tecnologías en lación al número de empleados en cada gestión de calidad, actividades de gestión empresa se mantiene casi igual en todos de producción, gestión ambiental, tecnololos segmentos. Esto indica que, de acuerdo con esta muestra de estudio, en Colombia las empresas de la industria manufacturera aún no reconocen la importancia de la formación académica como factor clave para la innovación.

Es interesante observar que la relación entre los esfuerzos de capacitación y la inversión de capital extranjero en actividades gías de administración, y proyectos de $\mathrm{I}+\mathrm{D}$, mientras que los esfuerzos de capacitación incluyen entrenamiento técnico. Esto sugiere que las empresas manufactureras en Colombia prefieren orientar sus gastos en actividades directas del negocio en lugar de en procesos de entrenamiento especializado a sus empleados. 
Tabla 6. Resumen comparativo por segmento de empresa

\begin{tabular}{lrrrr}
\hline Variable & Micro & Pequeña & Mediana & Grande \\
\hline Inversión en capacitación 2003-2004 (Sí/No) & $28 \%$ & $48 \%$ & $69 \%$ & $82 \%$ \\
Monto capacitación total por personal ocupado* & 93 & 137 & 169 & 266 \\
Inversión en actividades de innovación 2003-2004 & & & & \\
(Sí/No) & $23 \%$ & $41 \%$ & $60 \%$ & $78 \%$ \\
Monto inversión en actividades de innovación por & & & & \\
personal ocupado* & 1.418 & 1.079 & 1.251 & 2.263 \\
Reconocimiento de fuentes externas (Sí/No) & $30 \%$ & $45 \%$ & $59 \%$ & $72 \%$ \\
Número de fuentes externas reconocidas & 1,3 & 2,3 & 3,3 & 4,6 \\
Resultados de innovación (Sí/No) & $62 \%$ & $76 \%$ & $80 \%$ & $86 \%$ \\
Número de resultados de innovación & 4,8 & 8,3 & 11,2 & 18,2 \\
Años promedio de educación & 10,8 & 10,7 & 10,8 & 11,2 \\
Número de Doctores (Ph.D.) & - & - & 0,3 & 0,3 \\
Número de profesionales (o más) & 0,9 & 3,1 & 13,0 & 86,0 \\
Proporción de profesionales (o más) & $16 \%$ & $14 \%$ & $13 \%$ & $15 \%$ \\
Número de técnicos Sena & 0,7 & 2,5 & 10,0 & 69,0 \\
\hline Proporción de técnicos Sena & $11 \%$ & $11 \%$ & $10 \%$ & $11 \%$ \\
\hline
\end{tabular}

Nota. ${ }^{\star}$ Las cifras de capacitación monto por personal ocupado e inversión actividades en innovación por personal ocupado están en miles de pesos colombianos.

\subsection{Análisis de clúster por nivel de educación} Para los cuatro segmentos (micro, pequeñas, medianas y grandes empresas) se realizaron agrupaciones por nivel educativo con el método de clúster. Como resultado, los conglomerados muestran agrupaciones claras con relación al porcentaje de profesionales y técnicos y las diferencias ente los grupos fueron significativas estadísticamente (ver Gráfico 1).

Los clústeres se definieron de acuerdo a la proporción de profesionales, técnicos y personal sin formación académica, con la siguiente denominación: clúster 1 (empresas con bajo nivel de educación), clúster 2 (empresas con técnicos), clúster 3 (empresas con profesionales). El análisis de diferenciación de conglomerados para cada segmento por el método de k-medias muestra que estos grupos son estadísticamente diferentes entre sí. La diferencia de medias de los conglomerados por nivel educativo en cada segmento fue significativa al 0,05.

El principal factor que muestran estos clústeres es una concentración alta de personal sin formación (bajo nivel de educación) en todas los segmentos ( $76 \%$ de las empresas) (ver Tabla 7). Esto indica que las empresas manufactureras de Colombia, sin importar su tamaño, no cuentan con suficiente personal calificado. Sorprende que este resultado no varíe en el caso de las empresas grandes, donde se esperaría mayor reconocimiento de la formación académica. También se aprecia que, en general, hay más profesionales que técnicos ( $16 \%$ y $9 \%$, respectivamente) en las empresas, lo cual puede sugerir que en términos de formación, el empresario industrial colombiano valora más la educación formal que el entrenamiento técnico. 
Gráfico 1. Clústeres por nivel de educación en cada segmento de empresas

Microempresas

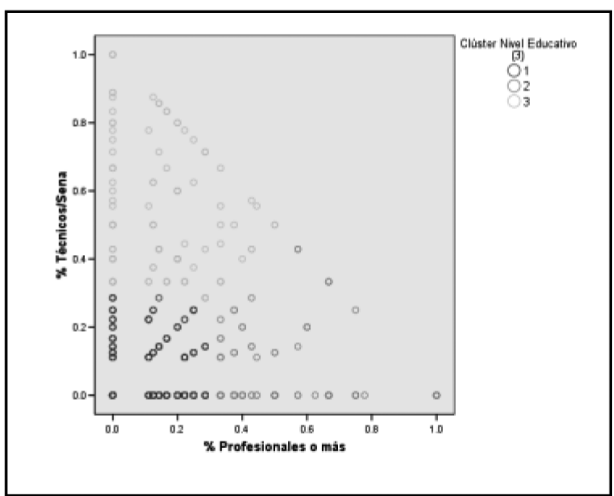

Medianas

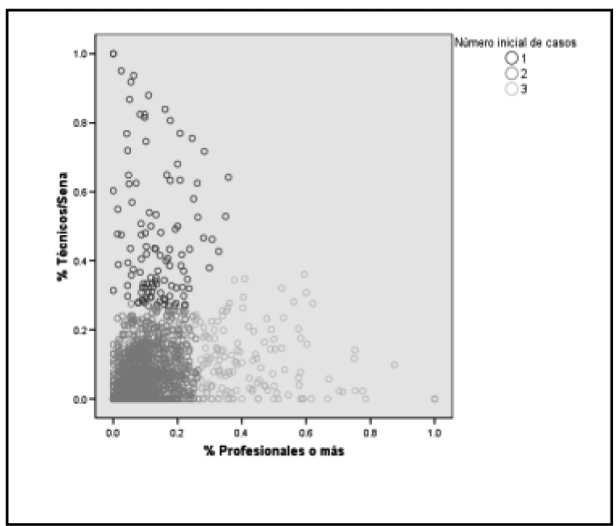

Pequeñas

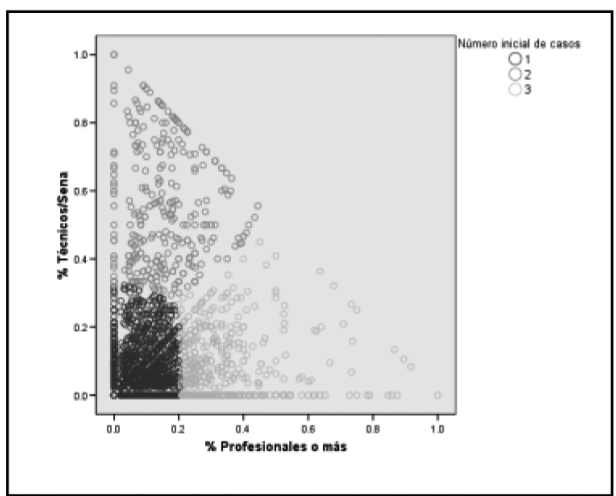

Grandes

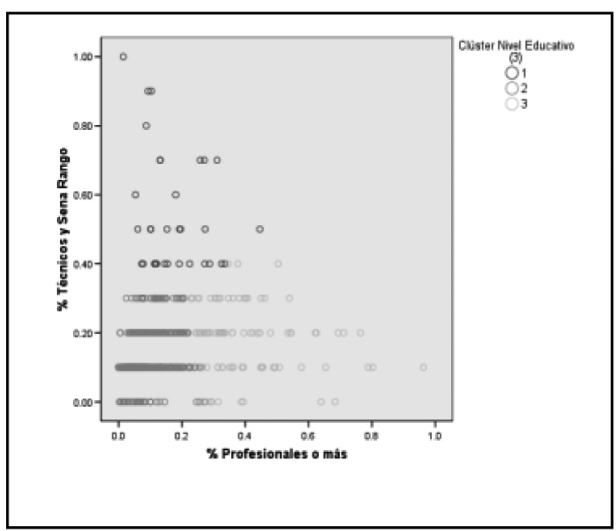

Leyendas por segmento

\begin{tabular}{lllll}
\hline Clúster & Micro & Pequeña & Mediana & Grande \\
\hline 1 & Bajo nivel de educ. & Bajo nivel de educ. & Técnicos & Técnicos \\
2 & Profesionales & Técnicos & Bajo nivel de educ. & Bajo nivel de educ. \\
3 & Técnicos & Profesionales & Profesionales & Profesionales \\
\hline
\end{tabular}

Fuente: Elaboración propia.

A continuación se presentan los análisis de las relaciones entre los conglomerados de nivel educativo y las variables de interés (resultados de innovación, redes externas, capacitación, inversión en actividades de innovación y capital extranjero), para cada una de los segmentos de empresas.

\section{Microempresas}

Se realizaron comparaciones de medias entre los diferentes conglomerados con relación a cada una de las cuatro variables de interés (ver Tabla 8). La comparación de medias con relación a resultados de innovación indica que existen diferencias significativas entre el clúster de bajo nivel de educación y el de 
Tabla 7. Resumen de clústeres por nivel educativo

\begin{tabular}{lccccc}
\hline Clúster nivel educativo & Micro & Pequeña & Mediana & Grande & Total \\
\hline Bajo nivel de educación & 587 & 2.342 & 1.306 & 456 & 4.691 \\
& $72 \%$ & $72 \%$ & $83 \%$ & $78 \%$ & $76 \%$ \\
Técnicos & 104 & 293 & 112 & 34 & 543 \\
& $13 \%$ & $9 \%$ & $7 \%$ & $6 \%$ & $9 \%$ \\
Profesionales & 125 & 606 & 151 & 96 & 978 \\
& $15 \%$ & $19 \%$ & $10 \%$ & $16 \%$ & $16 \%$ \\
\hline Total & 816 & 3.241 & 1.569 & 586 & 6.212 \\
\hline
\end{tabular}

Tabla 8. Comparación de medias en las microempresas (ANOVAs)

\begin{tabular}{|c|c|c|c|c|c|c|c|c|}
\hline \multirow{2}{*}{ Variables } & \multicolumn{2}{|c|}{$\begin{array}{l}\text { Bajo nivel de } \\
\text { educación }\end{array}$} & \multicolumn{2}{|c|}{ Técnicos } & \multicolumn{2}{|c|}{ Profesionales } & \multirow{2}{*}{$\mathrm{F}$} & \multirow{2}{*}{ Sig. } \\
\hline & Media & $\begin{array}{l}\text { Desv. } \\
\text { Típ }\end{array}$ & Media & $\begin{array}{l}\text { Desv. } \\
\text { Típ }\end{array}$ & Media & $\begin{array}{l}\text { Desv. } \\
\text { Típ }\end{array}$ & & \\
\hline $\begin{array}{l}\text { Número resultados } \\
\text { de innovación por } \\
\text { personal ocupado }\end{array}$ & 0,65 & 1,29 & 0,69 & 0,99 & 1,54 & 3,46 & $6.574,00$ & $0,002^{*}$ \\
\hline $\begin{array}{l}\text { Número fuentes } \\
\text { externas recono- } \\
\text { cidas por personal } \\
\text { ocupado }\end{array}$ & 0,18 & 0,54 & 0,24 & 0,76 & 0,44 & 1,10 & $7.550,00$ & $0,001^{*}$ \\
\hline $\begin{array}{l}\text { Capacitación monto } \\
\text { por personal ocu- } \\
\text { pado }\end{array}$ & 81,30 & 763,82 & 113,15 & 458,93 & 131,71 & 490,43 & 0,32 & 0,727 \\
\hline $\begin{array}{l}\text { Inversión activi- } \\
\text { dades innovación } \\
\text { monto por personal } \\
\text { ocupado }\end{array}$ & 957,35 & $7.551,96$ & 880,14 & $4.675,71$ & $4.027,20$ & $18.795,50$ & 5,14 & $0,006^{*}$ \\
\hline $\begin{array}{l}\text { Porcentaje inversión } \\
\text { capital social priva- } \\
\text { do extranjero }\end{array}$ & 0,10 & 2,47 & 0,48 & 4,90 & 0,80 & 8,94 & $1.427,00$ & 0,241 \\
\hline
\end{tabular}

Nota. ${ }^{\star}$ Tukey diferencia significativa al nivel 0,5.

profesionales, aumentando la media del pri- fuentes externas y la inversión en actividades mero al segundo. El mismo comportamiento de innovación son mayores para el clúster se aprecia para fuentes externas y para inver- que tiene más profesionales. siones en actividades de innovación. Estas últimas muestran un aumento significativo del clúster de técnicos al clúster de profesionales. Los grupos no se diferenciaron ni con relación a la capacitación ni al capital social privado extranjero. En general, se puede Pequeñas

En este segmento los análisis de comparación de medias para los tres grupos de conglomerados presentan diferencias significativas con relación a cada una de las cinco variables decir que los resultados de innovación, las de interés (ver Tabla 9). Se aprecia que las 
Tabla 9. Comparación de medias en las pequeñas empresas (ANOVAs)

\begin{tabular}{|c|c|c|c|c|c|c|c|c|}
\hline \multirow[t]{2}{*}{ Variables } & \multicolumn{2}{|c|}{$\begin{array}{c}\text { Bajo nivel } \\
\text { de educación }\end{array}$} & \multicolumn{2}{|c|}{ Técnicos } & \multicolumn{2}{|c|}{ Profesionales } & \multirow[t]{2}{*}{ F } & \multirow[t]{2}{*}{ Sig. } \\
\hline & Media & Desv. Típ & Media & Desv.Típ & Media & Desv.Típ & & \\
\hline $\begin{array}{l}\text { Número resultados } \\
\text { de innovación por } \\
\text { personal ocupado }\end{array}$ & 0,34 & 0,62 & 0,53 & 1,10 & 0,50 & 0,83 & 12,80 & $0,000^{*}$ \\
\hline $\begin{array}{l}\text { Número fuentes } \\
\text { externas reconocidas } \\
\text { por personal ocupado }\end{array}$ & 0,10 & 0,21 & 0,14 & 0,26 & 0,15 & 0,27 & 11,14 & $0,000^{*}$ \\
\hline $\begin{array}{l}\text { Capacitación Monto } \\
\text { por personal ocupado }\end{array}$ & 84,56 & 252,08 & 326,24 & $3.341,40$ & 251,12 & $1.382,58$ & 8,77 & $0,000^{*}$ \\
\hline $\begin{array}{l}\text { Inversión actividades } \\
\text { innovación monto por } \\
\text { personal ocupado }\end{array}$ & 840,04 & $3.475,42$ & 858,20 & $2.713,99$ & $2.111,06$ & $10.136,86$ & 13,87 & $0,000^{*}$ \\
\hline $\begin{array}{l}\text { Porcentaje inversión } \\
\text { capital social privado } \\
\text { extranjero }\end{array}$ & 0,81 & 8,32 & 0,75 & 8,18 & 4,08 & 18,76 & 21,77 & $0,000^{*}$ \\
\hline
\end{tabular}

Nota. ${ }^{\star}$ Tukey diferencia significativa al nivel 0,5.

medias aumentan del clúster de menor nivel educativo (bajo nivel de educación) al de mayor nivel educativo (profesionales). En general, para las empresas pequeñas manufactureras estudiadas, se puede afirmar que los resultados en términos de innovación, conectividad con redes externas, esfuerzos de capacitación e inversión en actividades de innovación, así como la participación de capital extranjero, están relacionados positivamente con un mayor nivel educativo en las empresas. Particularmente, se aprecia un aumento notorio del conglomerado de técnicos al de profesionales en la inversión en actividades de innovación y en la inversión de capital privado.

\section{Medianas}

Al igual que para las anteriores muestras, la mayoría de los casos se concentra en el conglomerado de menor nivel educativo, lo cual indica que las empresas manufactureras medianas estudiadas no cuentan con altas proporciones de personal muy calificado. Los análisis de comparación de medias indican que los tres conglomerados se diferencian entre sí con relación al número de fuentes externas reconocidas, inversión promedio en capacitación, inversión promedio en actividades de innovación y porcentaje de inversión de capital social privado extranjero (ver Tabla 10). El análisis de diferencia de medias indica que para el reconocimiento de fuentes externas, la inversión promedio en capacitación, la inversión en actividades de innovación y el porcentaje de capital extranjero, el grupo de menor nivel educativo presenta menores resultados (medias) que el grupo de profesionales. Estas diferencias son más notorias entre el conglomerado de técnicos y el de profesionales, particularmente para el caso de número de fuentes externas reconocidas e inversión promedio en capacitación.

\section{Grandes}

El análisis de comparación de medias indica que solo existen diferencias significativas entre los conglomerados de nivel educativo para el caso de capacitación, inversión en 
Tabla 10. Comparación de medias en las medianas empresas (ANOvAs)

\begin{tabular}{|c|c|c|c|c|c|c|c|c|}
\hline \multirow{2}{*}{ Variables } & \multicolumn{2}{|c|}{$\begin{array}{c}\text { Bajo nivel } \\
\text { de educación }\end{array}$} & \multicolumn{2}{|c|}{ Técnicos } & \multicolumn{2}{|c|}{ Profesionales } & \multirow{2}{*}{ F } & \multirow{2}{*}{ Sig. } \\
\hline & Media & $\begin{array}{l}\text { Desv. } \\
\text { Típ }\end{array}$ & Media & Desv. Típ & Media & Desv. Típ & & \\
\hline $\begin{array}{l}\text { Número resultados } \\
\text { de innovación por } \\
\text { personal ocupado }\end{array}$ & 0,12 & 0,19 & 0,16 & 0,25 & 0,15 & 0,20 & 2,75 & 0,065 \\
\hline $\begin{array}{l}\text { Número fuentes } \\
\text { externas reconocidas } \\
\text { por personal ocupado }\end{array}$ & 0,04 & 0,05 & 0,04 & 0,06 & 0,05 & 0,06 & 4,09 & $0,017^{\star}$ \\
\hline $\begin{array}{l}\text { Capacitación monto } \\
\text { por personal ocupado }\end{array}$ & 148,71 & 852,54 & 166,60 & 380,52 & 345,39 & 456,19 & 4,06 & $0,017^{\star}$ \\
\hline $\begin{array}{l}\text { Inversión actividades } \\
\text { innovación monto por } \\
\text { personal ocupado }\end{array}$ & $1.109,54$ & $6.377,19$ & $1.277,52$ & $3.971,66$ & $2.453,19$ & $8.144,99$ & 2,95 & $0,052^{*}$ \\
\hline $\begin{array}{l}\text { Porcentaje inversión } \\
\text { capital social privado } \\
\text { extranjero }\end{array}$ & 4,66 & 18,81 & 9,99 & 28,33 & 30,53 & 44,15 & 84,71 & $0,000^{*}$ \\
\hline
\end{tabular}

Nota. ${ }^{\star}$ Tukey diferencia significativa al nivel 0,5.

actividades de innovación y porcentaje de capital privado extranjero (ver Tabla 11). En estos tres casos las medias aumentaron desde el grupo de menor nivel educativo al grupo de mayor nivel educativo (profesionales). Por último, la inversión en capacitación y el capital extranjero aumentan desde el grupo de empresas con técnicos al de empresas con profesionales.

\section{Análisis comparativo}

Se aprecian dos aspectos relevantes. En primer lugar, que el conglomerado de mayor concentración de casos para cada variable estudiada es el las empresas con menor nivel educativo. Esto indica que las empresas manufactureras de Colombia estudiadas no cuentan con una mayoría de personal calificado. En segundo lugar, que después de aislar el segmento de bajo nivel educativo, se encuentra que entre mayor sea el tamaño de la empresa y mayor sea su proporción de profesionales, mayores son los indicadores asociados con la innovación.
El resumen de comparación de medias con los tres conglomerados de nivel educativo muestra diferencias de medias significativas para todas las variables de estudio (ver Tabla 12). Particularmente, se aprecia que las medias de las variables de estudio aumentan del conglomerado de empresas con bajo nivel educativo al de empresas con profesionales. Esto significa que las empresas que cuentan con un capital humano más alto, tienen más probabilidad de lograr resultados de innovación, conectarse en red, invertir en capacitación, en actividades de innovación y recibir capital extranjero.

La relación entre los conglomerados de nivel educativo y las variables de interés muestra un patrón similar para los cuatro segmentos por tamaño de empresa, esto es, los valores de las variables incrementan a medida que se pasa al conglomerado con capital humano más alto. Con relación al capital extranjero, hay variaciones marcadas entre cada conglomerado para los diferentes segmentos de empresas. En los segmentos de empresas micro y pequeñas 
Tabla 11. Comparación de medias en las grandes empresas (ANOVAs)

\begin{tabular}{|c|c|c|c|c|c|c|c|c|}
\hline \multirow[t]{2}{*}{ Variables } & \multicolumn{2}{|c|}{$\begin{array}{c}\text { Bajo nivel } \\
\text { de educación }\end{array}$} & \multicolumn{2}{|c|}{ Técnicos } & \multicolumn{2}{|c|}{ Profesionales } & \multirow[t]{2}{*}{$\mathrm{F}$} & \multirow[t]{2}{*}{ Sig. } \\
\hline & Media & Desv. Típ & Media & Desv. Típ & Media & Desv. Típ & & \\
\hline $\begin{array}{l}\text { Número resultados } \\
\text { de innovación por } \\
\text { personal ocupado }\end{array}$ & 0,04 & 0,07 & 0,06 & 0,09 & 0,05 & 0,06 & 0,42 & 0,655 \\
\hline $\begin{array}{l}\text { Número fuentes } \\
\text { externas reconocidas } \\
\text { por personal ocupado }\end{array}$ & 0,01 & 0,01 & 0,01 & 0,01 & 0,01 & 0,01 & 1,31 & 0,271 \\
\hline $\begin{array}{l}\text { Capacitación monto } \\
\text { por personal ocupado }\end{array}$ & 190,05 & 597,21 & 253,08 & 441,64 & 635,01 & $1.016,07$ & 17,04 & $0,000^{*}$ \\
\hline $\begin{array}{l}\text { Inversión actividades } \\
\text { innovación monto } \\
\text { por personal ocupado }\end{array}$ & $1.551,95$ & $5.167,78$ & $2.379,38$ & $7.745,37$ & $5 \cdot 597,20$ & $14.548,50$ & 11,05 & $0,000^{*}$ \\
\hline $\begin{array}{l}\text { Porcentaje inversión } \\
\text { capital social privado } \\
\text { extranjero }\end{array}$ & 15,72 & 33,64 & 19,19 & 33,35 & 45,97 & 46,36 & 28,00 & $0,000^{*}$ \\
\hline
\end{tabular}

Nota. ${ }^{\star T u k e y ~ d i f e r e n c i a ~ s i g n i f i c a t i v a ~ a l ~ n i v e l ~ 0,5 . ~}$

la inversión de capital extranjero es muy baja. Esta inversión empieza a ser visible en las medianas empresas y la proporción de empresas con inversión de capital extranjero es más notoria en las grandes. En este caso, es fácil deducir que el tamaño de la empresa influye notoriamente en la posibilidad que cuenten con participación de capital privado extranjero. Entre más grande sea una compañía, más solidez y respaldo muestra a los inversionistas, generándoles confianza.

Con relación a los resultados de innovación, hay diferencias significativas entre el conglomerado de profesionales y los otros dos (técnicos y bajo nivel de educación) en el segmento de microempresas $(F=6,57$, $\mathrm{p}<0,001), y$ diferencias significativas entre el conglomerado de bajo nivel de educación con los conglomerados de técnicos y profesionales en las pequeñas empresas $(\mathrm{F}=12,8 \mathrm{O}$, $\mathrm{p}<0,001)$. Esto es, un mayor nivel de educación está relacionado con más resultados de innovación comparada con una formación técnica o baja formación académica, lo cual soporta la hipótesis 1.
La inversión en capacitación difiere según el nivel de formación de sus empleados en los segmentos de pequeñas, medianas y grandes empresas. En las microempresas no hay diferencias significativas. En las empresas pequeñas hay más inversión en el grupo de técnicos, el cual difiere significativamente de los demás en este rubro. En las empresas medianas y grandes, el conglomerado de profesionales difiere significativamente de los demás y es el conglomerado que más se relaciona con inversión en capacitación; es decir, entre más grande sea la empresa, más probabilidad hay que se invierta en entrenamiento y esta inversión es mayor en la medida que el personal sea más calificado, lo cual soporta la hipótesis 2.

Con relación a la conectividad con redes externas, los análisis indican que entre más calificado sea el personal de las empresas (profesionales) mayor es el reconocimiento de de fuentes externas para la innovación, lo cual soporta la hipótesis 3. Esta diferencia es más notoria en las microempresas que en los otros segmentos de empresas. 
Tabla 12. Resumen de comparación de medias entre los conglomerados por nivel de educación en cada segmento de empresas

\begin{tabular}{|c|c|c|c|c|c|}
\hline \multirow[t]{2}{*}{ Variables } & $\begin{array}{c}\text { Bajo nivel } \\
\text { de educación }\end{array}$ & Técnicos & Profesionales & \multirow[t]{2}{*}{$\mathrm{F}$} & \multirow[t]{2}{*}{ Sig. } \\
\hline & Media & Media & Media & & \\
\hline \multicolumn{6}{|c|}{ Número resultados de innovación por personal ocupado } \\
\hline Microempresas & $0,65(1,29)$ & $0,69(0,99)$ & $1,54(3,46)$ & 6,57 & $0,002^{*}$ \\
\hline Pequeñas & $0,34(0,62)$ & $0,53(1,10)$ & $0,50(0,83)$ & 12,80 & $0,000^{*}$ \\
\hline Medianas & $0,12(0,19)$ & $0,16(0,25)$ & $0,15(0,20)$ & 2,75 & 0,065 \\
\hline Grandes & $0,04(0,07)$ & $0,06(0,09)$ & $0,05(0,06)$ & 0,42 & 0,655 \\
\hline \multicolumn{6}{|c|}{ Número fuentes externas reconocidas por personal ocupado } \\
\hline Microempresas & $0,18(0,54)$ & $0,24(0,76)$ & $0,44(1,10)$ & 7,55 & $0,001^{*}$ \\
\hline Pequeñas & $0,10(0,21)$ & $0,14(0,26)$ & $0,15(0,27)$ & 11,14 & $0,000^{*}$ \\
\hline Medianas & $0,04(0,05)$ & $0,05(0,04)$ & $0,06(0,05)$ & 4,09 & $0,017^{\star}$ \\
\hline Grandes & $0,01(0,01)$ & $0,01(0,01)$ & $0,01(0,01)$ & 1,31 & 0,271 \\
\hline \multicolumn{6}{|c|}{ Capacitación monto por personal ocupado } \\
\hline Microempresas & $81,30(763,82)$ & $113,15(458,93)$ & $131,71(490,43)$ & 0,32 & 0,727 \\
\hline Pequeñas & $84,56(252,08)$ & $326,24(3341,40)$ & $251,12(1382,58)$ & 8,77 & $0,000^{*}$ \\
\hline Medianas & $148,71(852,54)$ & $166,60(380,52)$ & $345,39(456019)$ & 4,06 & $0,017^{*}$ \\
\hline Grandes & $190,05(597,21)$ & $253,88(441,64)$ & $635,01(1016,1)$ & 17,04 & $0,000^{*}$ \\
\hline \multicolumn{6}{|c|}{ Inversión actividades innovación monto por personal ocupado } \\
\hline Microempresas & $957,35(7551,96)$ & $880,14(4675,71)$ & $4027,20(18795,50)$ & 5,14 & $0,006^{*}$ \\
\hline Pequeñas & $840,04(3475,42)$ & $858,20(2714,39)$ & $2111,06(10136,86)$ & 13,87 & $0,000^{*}$ \\
\hline Medianas & $1109,54(6377,19)$ & $1277,52(3972,66)$ & $2453,19(8144,99)$ & 2,95 & $0,052^{\star}$ \\
\hline Grandes & $1551,95(5167,78)$ & $2379,38(7745,37)$ & $5597,20(14548,50)$ & 11,05 & $0,000^{*}$ \\
\hline \multicolumn{6}{|c|}{ Porcentaje inversión capital social privado extranjero } \\
\hline Microempresas & $0,10(2,47)$ & $0,48(4,90)$ & $0,80(8,94)$ & 1,42 & 0,241 \\
\hline Pequeñas & $0,81(8,32)$ & $0,75(8,18)$ & $4,08(18,76)$ & 21,77 & $0,000^{*}$ \\
\hline Medianas & $4,66(18,81)$ & $9,99(28,33)$ & $30,53(44,15)$ & 84,71 & $0,000^{*}$ \\
\hline Grandes & $15,72(33,64)$ & $19,19(33,35)$ & $45,97(46,36)$ & 28,00 & $0,000^{*}$ \\
\hline
\end{tabular}

Nota. ${ }^{*}$ Tukey diferencia significativa al nivel 0,5.

La inversión en actividades de innova- profesionales y los demás conglomerados ción aumenta a medida que aumenta la para todos los segmentos de empresas proporción de personal calificado en las $(\mathrm{F}=5,14$ en las microempresas, $\mathrm{F}=13,87$ en empresas, soportando la hipótesis 4 . La las pequeñas, $\mathrm{F}=2,95$ en las medianas, y comparación de medias entre los conglo- $\mathrm{F}=11,05$ en las grandes, todas significativas merados por nivel educativo muestra una al nivel 0,05 ).

diferencia significativa entre el conglome- La inversión de capital extranjero aumenrado de empresas con mayor proporción de ta visiblemente de las empresas con técnicos 
a las empresas con profesionales y las diferencias entre los grupos son significativas en los segmentos de pequeñas, medianas y grandes empresas. Con esto se soporta la hipótesis 5.

\section{Conclusiones}

El objetivo de este estudio era explorar las relaciones entre el capital humano de las empresas industriales colombianas y los factores asociados con la innovación. Para esto se analizó la relación entre el nivel educativo y otros factores como resultados de innovación, vínculos con redes externas, la inversión en capacitación y actividades de innovación, y la participación de capital social privado extranjero, tomando como fuente de información la base de datos sobre innovación tecnológica en empresas manufactureras de Colombia.

A partir de una segmentación de los datos por tamaño de empresa (microempresas, pequeñas, medianas y grandes), se realizó una clasificación por conglomerados por nivel educativo para cada segmento identificándose en cada caso tres grupos claramente definidos: empresas con bajo nivel educativo, empresas con predominancia de técnicos y empresas con predominancia de profesionales. Se encuentran varios resultados relevantes. El primero, que un mayor nivel de formación académica en las empresas industriales está asociado con mayores resultados de innovación y con factores asociados con la innovación tales como mayor inversión en capacitación, mayor conectividad con redes externas, mayor inversión en actividades de innovación y participación de capital privado extranjero. Los resultados mostraron que, dentro de cada tamaño de empresa, estas variables aumentaban del conglomerado de empresas con bajo nivel de educación al conglomerado de empresas con profesionales.
El segundo resultado relevante es que las diferencias más notorias se encontraron con relación a la inversión en capacitación, inversión en actividades de innovación e inversión de capital extranjero. Estas diferencias fueron más visibles entre el grupo de empresas con técnicos y el de empresas con profesionales, en los segmentos de pequeñas, medianas y grandes empresas, sugiriendo que los esfuerzos que una empresa hace de manera más directa sobre los procesos de innovación, dependen de la base de personal calificado con que cuenten. Lo anterior sugiere que para este tipo de inversiones la formación técnica básica no es suficiente y se requiere contar con personal con nivel de formación académica formal.

Por otro lado, con relación a la cantidad de técnicos y profesionales en las empresas manufactureras, se aprecia una mayor proporción de personal profesional que de técnicos, sugiriendo que las empresas que invierten en personal calificado optan por contar con personas con formación académica formal. Esta proporción es más alta en las empresas pequeñas, lo cual resulta alentador ya que el 50\% de las empresas manufactureras en Colombia son categorizadas como pequeñas.

Finalmente, a pesar de que la proporción de profesionales es mayor que la de técnicos en todos los segmentos de las empresas manufactureras colombianas, el mayor porcentaje de personal ocupado no es suficientemente calificado. Esto se vio reflejado en que los conglomerados más grandes dentro de cada segmento por tamaño de empresa estuvieron representados por el clúster de bajo nivel educativo (alrededor del 70\% en cada segmento). Esto es un factor preocupante, ya que sugiere que los esfuerzos que hacen las empresas manufactureras en Colombia están enfocados en productos y procesos comunes que requieren pocos 
conocimientos y que no generan un valor agregado importante al desarrollo económico del sector y del país.

Según Stam \& Nooteboom (2011) las actividades de innovación en las organizaciones son un reflejo del conocimiento de la sociedad en la que operan, creando un círculo virtuoso en el que el conocimiento de la sociedad se va enriqueciendo en la medida que las organizaciones lo exploten y generen procesos innovadores. El que el personal profesional en la industria manufacturera colombiana sea en promedio el $16 \%$ del personal ocupado, sugiere que la probabilidad de que el conocimiento formal juegue un papel importante en los procesos innovadores es baja aún si se asume (no se conoce a través de la encuesta) que este porcentaje estuviera ocupado en actividades de innovación.

\section{Discusión}

A pesar de las diferencias significativas entre los diferentes clústeres frente a los indicadores estudiados (resultados de innovación, vínculos con redes externas, inversión en capacitación y en actividades de innovación, y participación de capital social privado extranjero), los resultados en estos indicadores fueron relativamente bajos, donde, con excepción de las grandes empresas, la mayoría están por debajo del 50\%.

Lo anterior podría estar asociado con la gran proporción de personal con bajo nivel educativo en todos los segmentos de empresas manufactureras estudiadas. Este personal está caracterizado por contar con una formación escolar básica que muchas veces no llega a la secundaria. Esta situación deja pocas posibilidades de generarse dinámicas de aprendizaje y generación de conocimiento que puedan generar impacto en los procesos de innovación de las organizaciones. Por lo tanto, los procesos inno- vadores y por ende la capacidad innovadora de las empresas manufactureras, podría potenciarse haciendo un uso más apropiado y dinámico del conocimiento existente.

Según Audretsch (1995) la capacidad innovadora de una compañía se logra a través de los trabajadores del conocimiento. Esto es, empleados con educación superior que sepan aprovechar y desarrollar el conocimiento existente en la industria. Aquí juega un papel importante lo que se conoce como los difusores de conocimiento en los procesos innovadores (Audretsch \& Keilbach, 2006), los cuales son claves en el crecimiento económico (Grossman \& Helpman, 1991; Lucas, 1988; Romer, 1986). Acs, Audretsch \& Feldman (1994) argumentan que los procesos de difusión de conocimiento son útiles para promover la actividad innovadora en las grandes empresas y son decisivos para las empresas pequeñas, las cuales explotan el conocimiento que sale de las universidades y las grandes compañías. Esto se lograría no solo a través de una mayor contratación de profesionales y personal con educación formal alta, sino fortaleciendo las relaciones entre las empresas e instituciones que participan de una u otra forma en la industria. En este sentido, se estaría hablando del fortalecimiento de clústeres industriales. En resumen, se podría sugerir que la capacidad innovadora de las empresas manufactureras en Colombia se beneficiaría si las empresas reconocen los beneficios que trae para el aprendizaje y la innovación, el contar con personal con mayor educación, y la integración entre empresas y con empresas innovadoras grandes así como con las universidades.

Este estudio tiene varias limitaciones que impiden un análisis más amplio y generalizado. En primer lugar, los análisis incluyen asociaciones entre factores, en este caso, entre capital humano e innovación y activida- 
des asociadas con la innovación, no análisis de tendencias. Por lo tanto, los resultados deben tomarse como una aproximación a posibles determinantes de la innovación en las empresas manufactureras mas no como predicciones. En segundo lugar, debido a la estructura de la encuesta, no es factible identificar la participación directa del personal en los procesos de innovación según su capital humano, lo cual dificulta conocer la contribución específica del personal más calificado a los diferentes procesos y actividades asociadas con la investigación. Por otro lado, dado que este estudio se centra en analizar la situación de las empresas manufactureras en el año 2005 y no se contaba con estudios previos analizando las mismas relaciones en encuestas anteriores, no es posible identificar su evolución, en aras de identificar diferencias que puedan ser atribuidas al capital humano. Sin embargo, este estudio puede servir de base para comparativos posteriores en este sentido.

Este estudio analizó las empresas manufactureras en general con la sola separación por tamaño de empresa. Sería útil, en términos de estudiar la concentración y el aporte del capital humano a los procesos innovadores, analizar estos factores por sectores productivos. Es probable que en sectores más tecnológicos, el capital humano juegue un papel más relevante que en otros sectores. La incidencia del nivel educativo podría ser más directa y evidente en sectores que requieran mayor uso de tecnologías. Otra línea de investigación futura puede ser estudiar características del sector manufacturero por clústeres y comparar su capacidad innovadora analizando factores como su capital humano y su estructura en términos del tipo de organizaciones con las que se relaciona y la fortaleza de sus relaciones. En este sentido, podría ser un estudio la capacidad innovadora de los clústeres de manufactura en Colombia desde el enfoque de redes y capital social (que se construye a partir de la interacción del capital humano de las empresas en el clúster). Por otro lado, una línea de investigación puede orientarse a realizar estudios comparativos de la composición e incidencia del capital humano en la capacidad innovadora de sectores industriales manufactureros entre diferentes países en vías de desarrollo, o en Latino-América.

Finalmente, los resultados de este estudio tienen implicaciones prácticas. Las empresas deben vincular más personal calificado y procurar sostener los procesos de entrenamiento de su personal si quieren lograr ventajas competitivas en términos de innovaciones tecnológicas. Una adecuada integración entre la educación formal (conocimiento abstracto) y el entrenamiento (conocimiento aplicado) mejora el capital humano de la empresa y la puede llevar a resultados más notorios con relación a resultados de innovación y los factores asociados con la innovación. Sin embargo, tal vez los empresarios aún no tengan la suficiente confianza en este tipo de formación y el conocimiento que de allí se deriva, y prefieren intentar lidiar con los retos tecnológicos del mercado de una manera idiosincrática ya que, según Salazar (1998) las actividades de innovación en las empresas manufactureras colombianas son bastante informales.

\section{Referencias bibliográficas}

Acs, Z.J., Audretsch, D.B. \& Feldman, M.P. (1994). R\&D spillovers and recipient firm size. Review of Economics \& Statistics, $100(2), 336-367$.

Alcorta, L. \& Peres, W. (1998). Innovation systems and technological specialization in Latin America and the Caribbean. Research Policy, 26(7/8), 857-881. 
Argyris, C. \& Schon, D. (1978). Organizational learning: A theory of action perspective. Reading, MA: Addison-Wesley.

Arocena, R. \& Sutz, J. (2002). Sistemas de innovación y países en desarrollo. SUDESCA Research Papers, 30. Recuperado el 22 de julio de 2011, de http://www.oei. es/salactsi/arocenasutz.htm\#f

Arrow, K.J. (1962). The Economic implications of learning by doing. The Review of Economic Studies, 29(3), 155-173.

Audretsch, D.B. (1995). Innovation and industry evolution. Cambridge, MA: MIT Press.

Audretsch, D.B. \& Keilbach, M. (2006). Entrepreneurship capital and economic performance. En D.B. Audretsch (Ed.), Entrepreneurship, innovation and economic growth (pp. 293-303). Cheltenham, UK: Edward Elgar.

Bauernschuster, S., Falck, O. \& Heblich, S. (2009). Training and innovation. Journal of Human Capital, 3(4), 323-353.

Becker, G.S. (1964). Human capital. Chicago, IL: Chicago University Press.

Boer, H. \& During, W.E. (2001). Innovation, what innovation? A Comparison between product, process and organizational innovation. International Journal of Technology Management, 22(1/2/3), 83-107.

Brown, J.S. \& Duguid, P. (1991). Organizational learning and communities of practice: Toward a unified view of working, learning, and innovation. Organization Science, 2(1), 40-57.

Brown, J.S. \& Duguid, P. (1998). Organizing knowledge. California Management Review, 40(3), 90-111.

Brusoni, S., Cefis, E. \& Orsenigo, L. (2006). Innovate or die? A critical review of the literature on innovation and performance (Working paper 179, Centro di Ricerca sui Processi di Innovazione e Internazi- onalizzazione, Università Commerciale Luigi Bocconi).

Cassiolato, J.E. \& Lastres, H.M.M. (1999, junio). Local systems of innovation in the Mercosur Countries. Documento presentado en DRUID Summer Conference on National Innovation Systems, Industrial Dynamics and Innovation Policy, Danish Research Unit on Industrial Dynamics. Denmark. Disponible en http://www. druid.dk/uploads/tx_picturedb/ds199948.pdf

Ciruelos, A. \& Wang, M. (2005). International technology diffusion: Effects of trade and FDI. Atlantic Economic Journal, 33(4), 437-449.

Cohen, W. \& Levinthal, D. (1990). Absorptive capacity: A new perspective on learning and innovation. Administrative Science Quarterly, 35(1), 128-152.

Coleman, J.S. (1988). Social capital in the creation of human capital. The American Journal of Sociology, 94, 95-120.

Colombo, M. (2003). Alliance form: A test of the contractual and competence perspectives. Strategic Management Journal, 24(12), 1209-1229.

Dakhli, M. \& DeClercq, D. (2004). Human capital, social capital, and innovation: A multicounty study. Entrepreneurship \& Regional Development, 16(2), 107-128.

DANE. (2008). Departamento Administrativo Nacional de Estadística. Bogotá: Autores. Freeman, C. (1987). Technology policy and economic performance: Lessons from Japan. Londres: Frances Printer.

Fox, G.L. (2008). The role of human capital in predicting innovation. Society for Marketing Advances Proceedings, 291-292. Grossman, G.M. \& Helpman, E. (1991). Innovation and growth in the global economy. Cambridge, MA: MIT Press.

Hatch, N.W. \& Dyer, J.H. (2004). Human Capital and Learning as a source of sus- 
tainable competitive advantage. Strategic Management Journal, 25(12), 1155-1178. Hayes, R., Pisano, G. \& Upton, D. (1996). Strategic operations. Competing through capabilities. New York, NY: The Free Press.

Lam, A. (2005). Organizational innovation. En J. Fagerberg, D.C. Mowery \& R.R. Nelson (Eds.), The Oxford Handbook of innovation (pp.115-147). New York, NY: Oxford University Press.

Langebaek, A. \& Vásquez, D. (2007). Determinantes de la actividad innovadora en la industria manufacturera colombiana. Bo-rradores de Economía, 433, 1-36.

Link, A.N. \& Siegel, D.S. (2007). Innovation, entrepreneurship, and technological change. Oxford, uk: Oxford University Press.

Lucas, R.E. (1988). On the mechanisms of economic development. Journal of Monetary Economics, 22(1), 3-42.

Lucas, R.E. (1990). Why doesn't capital flow from rich to poor countries? American Economic Review, 80(2), 92-96.

McEvily, B. \& Marcus, A. (2005). Embedded ties and the acquisition of competitive capabilities. Strategic Management Journal, 26(11), 1033-1055.

Metcalfe, S. (2006). Innovation, competition, and enterprise: Foundations for economic evolution in learning countries. En J. Hage \& M. Meeus (Eds.). Innovation, science and institutional change: A research handbook (pp. 105-121). Oxford, UK: Oxford University Press.

Nonaka, I. (1994). A dynamic theory of organ-izational knowledge creation. Organization Science, 5(1), 14-37.

Nonaka, I. \& Takeuchi, H. (1995). The knowledge creating company. New York, NY: Oxford University Press.

OECD. (2007). Improving tertiary education. En OECD (Eds.), oECD Economic Surveys: Greece (Chapter 5, pp. 105-114). Paris: Autores.
Powell, W. \& Grodal, S. (2005). Networks of innovators. En J. Fagerberg, D.C. Mowery \& R.R. Nelson (Eds.), The Oxford Handbook of Innovation (pp.55-85). New York, NY: University Press.

Prahalad, C.K. \& Hamel, G. (1990). The core competence of the corporation. Harvard Business Review, 68(3), 79-91.

Romer, P.M. (1986). Increasing returns and long-run growth. Journal of Political Economy, 94(5), 1002-1037.

Rosenberg, N. (2002, septiembre). Sources of Innovation in developing countries. Reflections on the Asian Experience. En UNU \& Institute for New Technology (chair), Amilcar Herrera Public Lecture (Documento presentado no publicado), Maastricht, The Netherlands.

Salazar, M. (1998). Panorama de la innovación tecnológica en la industria colombiana. Revista de la ANDI, 151 (Marzo), 66-74.

Sanabria, R. (2005). Formulación y Pensamiento Estratégico. Bogotá: Planeta.

Schumpeter, J.A. (1947). The Creative Response in Economic History. The Journal of Economic History, 7(2), 149-159.

Shu, L. \& Teixeira, A.A.C. (2010). The level of human capital in innovative firms located in China. Is foreign capital relevant? (Working Paper No. 291). Porto: Faculdade de Economia da Universidade do Porto.

Stam, E. \& Nooteboom, B. (2011). Entrepreneurship, innovation and institutions. En D.B. Audretsch, O. Falck, S. Heblich \& A. Lederer (Eds.), Handbook of research on innovation and entrepreneurship (pp. 421-438). Cheltenham, UK: Edward Elgar.

Tavares, A.T. \& Teixeira, A.A.C. (2005). Human capital intensity in technology difference technology-based firms located in Portugal: Do foreign multinationals make a difference? (FEP Working Papers No. 187). Porto: Faculdade de Economia, Universidade do Porto. 
Teece, D.J., Pisano, G. \& Shuen, A. (1997). Dynamic capabilities and strategic management. Strategic Management Journal, 18(7), 509-533.

Thornhill, S. (2006). Knowledge, innovation and firm performance in high and lowtechnology regimes. Journal of Business Venturing, 21(5), 687-703.

Veryzer, R.W. (2005). The Roles of Marketing and Industrial Design in Discontinuous New Product Development. Journal of Product and Innovation Management, 22(1), 22-41.

Wenger, E. (1998). Communities of practice: Learning, meaning, and identity. New York, NY: Cambridge University Press.

Williams, J. (1994). Strategy and the search for rents: the evolution of diversity among firms. En R. Rumlet, D. Schendel \& D. Teece (Eds.), Organizational Capabilities (pp. 229-246). Boston, MA: Harvard Business School Press. 